\title{
POTENTIAL DISCRIMINANT FACTORS FOR DIFFERENT PCOS PHENOTYPES
}

\author{
Stojković M., Beleslin B., Ćirić J., Savić S., Nišić T., Lalić T., Stojanović M., Trbojević B. Žarković M. \\ Clinic of Endocrinology, Diabetes and Metabolic Diseases, Clinical Center of Serbia
}

Background: Polycystic ovary syndrome (PCOS) is one of the most common endocrine disorders in women of reproductive age. It is a heterogeneous disorder characterized by oligo- or anovulation (ANOV), biochemical or clinical manifestations of hyperandrogenemia (HA) and polycystic ovaries (PCO). Combination of these three characteristics makes four phenotypes of PCOS: phenotype 1 $(\mathrm{ANOV}+\mathrm{HA}+\mathrm{PCO})$, phenotype $2(\mathrm{ANOV}+\mathrm{HA})$, phenotype $3(\mathrm{HA}+\mathrm{PCO})$ and phenotype 4 $(\mathrm{ANOV}+\mathrm{PCO})$. The differences between these four phenotypes are still undefined and the subjects of study.

Methods: We evaluate 92 PCOS women using stepwise linear discriminant analysis with phenotype as dependent variable and BMI, FSH, LH, LTH, oestradiol, testosterone, progesterone, HDLcholesterol, LDL-cholesterol, HOMA IR and HOMA B as independent variables.

Results: The phenotype 1 was present in $32.6 \%$, phenotype 2 in $21 \%$, phenotype 3 in $28 \%$ and phenotype 4 in $14.1 \%$ of cases. We found that BMI, LH, HOMA IR and HOMA B were discriminante factors for different PCOS phenotypes, while the other variables didn`t reach statistically significant difference.

BMI HH HOMA IR HOMA B

$\begin{array}{lllll}\text { ANOV+PCO+HA } & 27.1 \pm 6.0 \mathrm{~kg} / \mathrm{m}^{2} ; & 7.33 \pm 4.69 \mathrm{IU} / \mathrm{L} ; & 1.49 \pm 0.34 ; & 371.8 \pm 391.7 ; \\ \text { ANOV+HA } & 29.2 \pm 8.0 \mathrm{~kg} / \mathrm{m}^{2} ; & 5.30 \pm 3.81 \mathrm{IU} / \mathrm{L} ; & 1.32 \pm 0.39 ; & 423.1 \pm 213.1 ; \\ \text { ANOV+PCO } & 22.8 \pm 4.4 \mathrm{~kg} / \mathrm{m}^{2} ; & 11.13 \pm 6.13 \mathrm{IU} / \mathrm{L} ; & 1.18 \pm 0.28 ; & 535.1 \pm 365.5 ; \\ \text { PCO+HA } & 24.9 \pm 5.8 \mathrm{~kg} / \mathrm{m}^{2} ; & 4.12 \pm 2.62 \mathrm{IU} / \mathrm{L} ; & 1.40 \pm 0.49 ; & 755.6 \pm 1436.2 ;\end{array}$

Conclusions: We concluded that LH, BMI, HOMA IR and HOMA B could be useful as discriminant factors in different PCOS phenotypes. 